\title{
The Diagnostic Accuracy of 18F-FDG PET/CT in Prostate Cancer: A Systemic Review and Meta-analysis
}

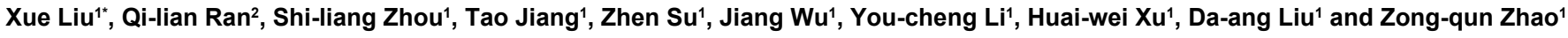 \\ ${ }^{1}$ Department of Nuclear Medicine, the First People's Hospital of Huaihua, Huaihua, Hunan, China
}

${ }^{2}$ Department of General Surgery, First Affiliated Hospital of Hunan University of Medicine, Huaihua, Hunan, China

\begin{abstract}
Objectives: A systematic review process was adopted to derive more robust estimates of the diagnostic accuracy of $18 \mathrm{~F}$-fluorodeoxyglucose(18F-FDG) positron emission tomography /computed tomography (PET/CT) for prostate cancer we pooled published studies.
\end{abstract}

Methods: A comprehensive literature search about published studies till November 2017 was performed. Methodological quality of each study was assessed. A meta-analysis was used to analyze the sensitivity, specificity, diagnostic odds ratio (DOR), area under the curve (AUC), summary receiver operating characteristic (SROC) curve and Q* indexes with statistical software.

Results: Ten articles including 364 patients and 505 lesions, which published between 2009 and 2017, met the inclusion criteria for the meta-analysis. The pooled sensitivity and specificity of 18F-FDG PET-CT in prostatic cancer were $0.65(95 \% \mathrm{Cl}, 0.47-0.79)$ and $0.85(95 \% \mathrm{Cl}, 0.71-0.93)$, respectively. The overall PLR, NLR and DOR were $4.3(95 \% \mathrm{Cl}, 2.0-9.2), 0.41(95 \% \mathrm{Cl}, 0.25-0.68)$ and $10(95 \% \mathrm{Cl}, 3-32)$, respectively. The area under the summary ROC curve was 0.84 . There is not exist publication bias in the included studies according to the Deek's test.

Conclusions: The results of our meta-analysis suggested that 18F-FDG PET-CT were imaging methods with high accuracy in differential diagnosis of prostate cancer patients.

Keywords: Prostate cancer; PET/CT; 18F-FDG; Meta-analysis

\section{Introduction}

Prostate cancer is the most common malignant tumor elderly male in the reproductive system [1]. Recently, the incidence of prostate cancer is very high and account for the highest incidence of all male cancers and the mortality rate is second in the Europe and American countries [2]. Early detection, early diagnosis and early treatment are the key to improve survival and quality of life for prostate cancer patients [2]. In terms of diagnosis, traditional medical imaging techniques, such as CT, MRI and ultrasound, have certain limitations in identified diagnosis of prostate cancer [3]. With the development of medical molecular biology technology, molecular imaging PET/CT is being used to diagnose prostate cancer. Compared with traditional medical diagnosis technology, PET/CT can detect early malignant lesions and evaluate the therapeutic effect after treatment [4]. Relevant studies [5-7] reported that the PET/CT has high application value on prostate cancer, but because of the different study results are huge so that there is not inconsistent conclusion because of the diversity of research population, different design method, and various regions. In order to derive more robust estimates of the diagnostic accuracy of 18F-FDG PET/ CT for prostate cancer in this setting we pooled published studies. A systematic review process was adopted in ascertaining studies, thereby avoiding selection bias.

\section{Materials and Methods}

\section{Data sources and search strategies}

A comprehensive computer literature search of PubMed, MEDLINE, and web of science and Embase databases were searched from January 1990 to November 2017 using the following searching strategy: ("fluorodeoxyglucose F18"[MeSH Terms] OR ("fluorodeoxyglucose"[All Fields] AND "F18"[All Fields]) OR "fluorodeoxyglucose F18"[All Fields] OR ("18F"[All Fields] AND "FDG"[All Fields]) OR "18F FDG"[All Fields]) AND PET/CT[All Fields] AND ("prostatic neoplasms"[MeSH Terms] OR ("prostatic"[All Fields] AND "neoplasms"[All Fields]) OR "prostatic neoplasms"[All Fields] OR ("tumor"[All Fields] AND "prostate"[All Fields]) OR "tumor of prostate"[All Fields]) OR ("cancer"[All Fields] AND "prostate"[All Fields]). Only articles in English language were considered. Besides, to expand our search, references of the retrieved articles were also screened for additional studies.

\section{Study selection}

Two investigators independently reviewed titles and abstracts of the eligible articles based on the inclusion criteria for this study: (a) articles which were open access English scientific literature; (b) articles which used 18F-FDG PET-CT to identify as prostatic cancer; (c) articles which used histopathology or follow-up at least 3 months as the reference standard; (d) articles which presented complete data to construct $2 \times$ 2 tables [this is, true positive (TP), true-negative (TN), false-positive (FP), and false-negative (FN)]; (e) sample size was more than 10; (f) the main object of articles were prostate disease and primary tumor. In contrast, articles were excluded if: (a) articles which were unable to

*Corresponding author: Xue Liu, Department of Nuclear Medicine, the First People's Hospital of Huaihua, Huaihua, Hunan, China, Tel: +0745-2382843; E-mail: yxliuxue@foxmail.com

Received January 27, 2018; Accepted January 30, 2018; Published February 07, 2018

Citation: Liu X, Qi-lian R, Shi-liang Z, Jiang T, Su Z, et al. (2018) The Diagnostic Accuracy of 18F-FDG PET/CT in Prostate Cancer: A Systemic Review and Metaanalysis. J Nucl Med Radiat Ther 9: 352. doi: 10.4172/2155-9619.1000352

Copyright: (c) 2018 Liu X, et al. This is an open-access article distributed under the terms of the Creative Commons Attribution License, which permits unrestricted use, distribution, and reproduction in any medium, provided the original author and source are credited. 
get the full text; (b) articles that were duplicates, conferences, reviews or case reports.

\section{Data extraction}

Data abstracted from each eligible article were collected in homemade Excel spread sheet included the following details: title, authors, year of publication, country, sample sizes(patients or lesions), age, design, reference, standard of diagnosis, Gleason scores, dose of 18F-FDG, et al. Each study was analyzed to retrieve the number of TP, FP, FP and TN findings of 18F-FDG PET/CT in patients with prostatic disease, according to the standard of diagnosis. Only studies providing such complete information were finally included in the meta-analysis. If the study analyzed the number of per-patient and per-lesion, we will extract the latter.

\section{Quality assessment}

The QUADAS (Quality Assessment of Diagnostic Accuracy Studies) checklist was used to assess independently the methodological quality by the same investigators [8]. This table is an evidence-based quality assessment tool which developed for systematic reviews about the diagnostic accuracy of studies [8].

\section{Statistical methods}

Statistically, the $\chi^{2}$-based $\mathbf{Q}$ statistic test (Cochran's $\mathbf{Q}$ statistic) was used to estimate whether existing study heterogeneity or not, and the $\mathrm{I}^{2}$ statistic was used to measure the magnitude of the heterogeneity. Generally, the smaller the $\mathrm{P}$ value of $\mathbf{Q}$ test, the larger the $\mathrm{I}^{2}$ statistic [9].
The $\mathrm{I}^{2}$ index was calculated to assess between-study heterogeneity. The values of $\mathrm{I}^{2}$ of $25 \%, 50 \%$ and $75 \%$ were considered as evidence of low, moderate, and high heterogeneity, respectively [10]. If the heterogeneity was low, the fixed-effects model was used to pool the results; otherwise, the random-effects model was used when $\mathrm{I}^{2}$ was more than $50 \%$ [10].

The pooled results included the items: sensitivity $\mathrm{TP} /(\mathrm{TP}+\mathrm{FN})$, specificity $\mathrm{TN} /(\mathrm{TN}+\mathrm{FP})$, positive likelihood ratio (PLR), negative likelihood ratio (NLR), diagnostic odds ratio (DOR) and 95\% confidence interval ( $95 \% \mathrm{CI})$. The results of the individual studies were displayed in receiver operating characteristic (ROC) space, a weighted symmetric sROC curve with $95 \%$ CI was computed with the Moses' constant of linear mode, and the value of AUC and $Q^{*}$ indexes (the point on the curve at which sensitivity and specificity are equal) as estimated [11]. Besides, if the heterogeneity of the study was caused by the threshold effect, the best method of pooling data is using summary receiver operating characteristic (sROC) curve and calculating the area under the curve (AUC) of ROC. If heterogeneity is caused by the nonthreshold effect, the data was combined by subgroup analysis or metaregression analysis. Besides, publication bias was assessed by using Deek's test [12].

Statistical analyses were performed with STATA software (version 12.0) [12] for the eligible studies.

\section{Results}

\section{Literature search}

The comprehensive computer literature search from the databases

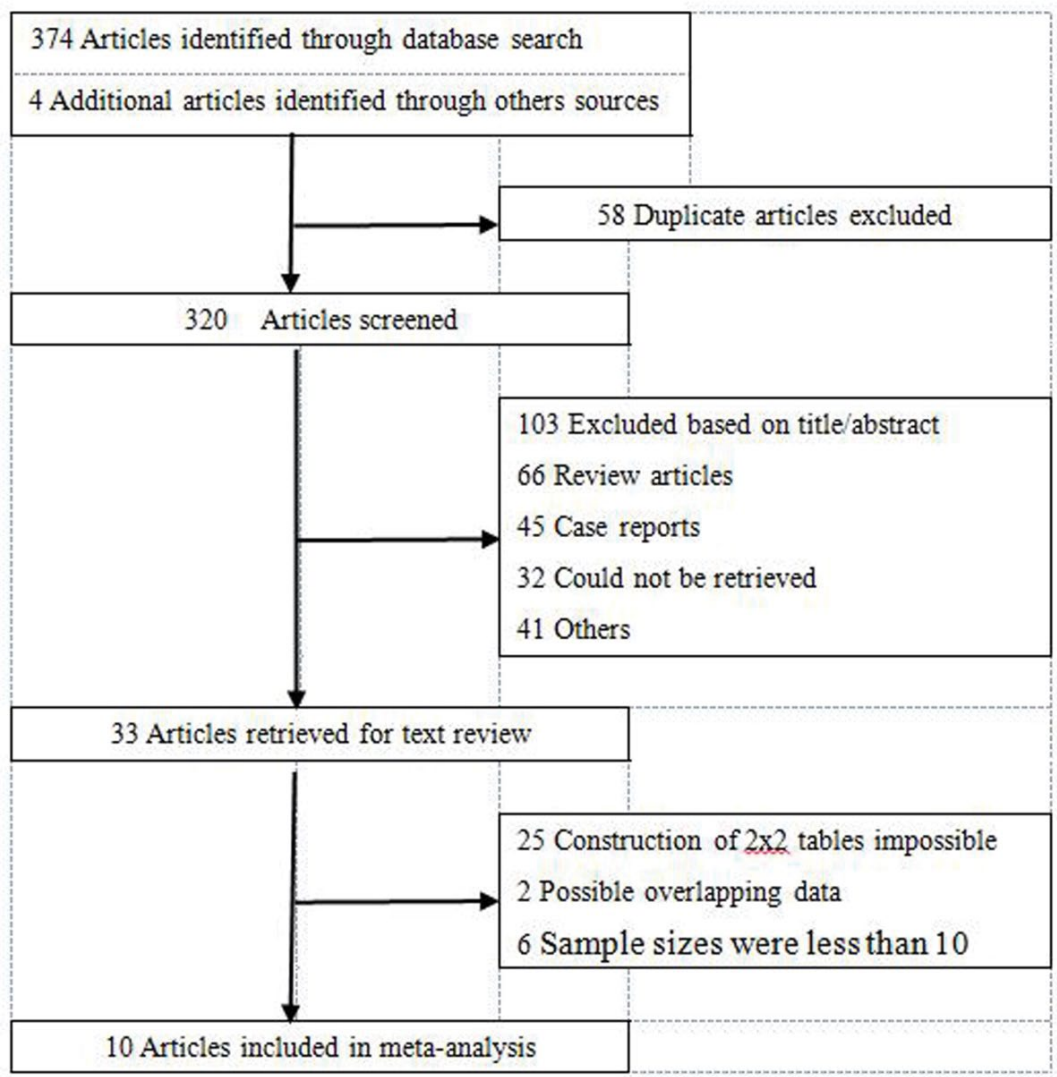

Figure 1: Literature Search of Eligible Studies. 


\begin{tabular}{|c|c|c|c|c|c|c|c|c|c|c|c|}
\hline Authors & $\begin{array}{c}\text { Publication } \\
\text { year }\end{array}$ & Country & $\begin{array}{c}\text { Age } \\
\text { (years) }\end{array}$ & $\begin{array}{c}\text { No. of } \\
\text { patients }\end{array}$ & $\begin{array}{l}\text { No. of } \\
\text { lesions }\end{array}$ & $\begin{array}{c}\text { Level of PSA } \\
(\mathbf{n g} / \mathrm{ml})\end{array}$ & Type & Reference & $\begin{array}{l}\text { Gleason } \\
\text { scores }\end{array}$ & $\begin{array}{c}\text { Dose of } \\
\text { FDG }(\mathrm{MBq})\end{array}$ & suv \\
\hline LIU et al. [5] & 2014 & USA & $61 \pm 9$ & 25 & NG & $291 \pm 363$ & $\mathrm{R}$ & Biopsy & $6-9$ & NG & $>3.0$ \\
\hline Richter et al. [14] & 2017 & Spain & $41-78$ & 73 & NG & 2.7 & $\mathrm{R}$ & Biopsy & $8-10$ & 370 & $4.8 \pm 1.9$ \\
\hline Kit et al. [7] & 2015 & Sweden & $63-78$ & 10 & 70 & $0.12-15$ & $\mathrm{R}$ & Biopsy, CT & $7-8$ & $4 \mathrm{MBq} / \mathrm{kg}$ & NG \\
\hline García et al. [15] & 2009 & Spain & $63.8 \pm 6.9$ & 38 & NG & $0.8-9.5$ & $\mathrm{R}$ & Biopsy & $8-10$ & $656 \pm 119$ & NG \\
\hline Beauregard et al. [13] & 2010 & USA & $51-77$ & 16 & NG & $0.09-795$ & $\mathrm{P}$ & Biopsy & $6-9$ & 300 & NG \\
\hline Minamimoto et al. [6] & 2015 & Canada & $68.3 \pm 9.4$ & 30 & 129 & $8.6 \pm 10.1$ & $\mathrm{P}$ & $\begin{array}{c}\text { Pathology, } \\
\text { clinical follow-up }\end{array}$ & NG & $\begin{array}{c}370.1 \pm \\
24.7\end{array}$ & NG \\
\hline Hossein et al. [17] & 2012 & Canada & 71.1 & 37 & NG & $53.5-86.9$ & $\mathrm{P}$ & Biopsy & $6-9$ & $\begin{array}{c}525.4 \pm \\
25.9\end{array}$ & NG \\
\hline Yi et al. [16] & 2016 & China & $60-88$ & 36 & 106 & $10.91-1000$ & $\mathrm{P}$ & $\begin{array}{c}\text { Pathology, } \\
\text { clinical follow-up }\end{array}$ & $8-10$ & $\begin{array}{c}5.18 \mathrm{MBq} / \\
\mathrm{kg}\end{array}$ & $\begin{array}{l}\text { Higher than } \\
\text { iliac fossa fat }\end{array}$ \\
\hline Ryogo et al. [18] & 2011 & Japan & $41-82$ & 50 & 200 & $15.9 \pm 14.9$ & $\mathrm{P}$ & biopsy & $>7$ & $2.5 \mathrm{MBq} / \mathrm{kg}$ & $>2.9$ \\
\hline Nishikant et al. [19] & 2013 & India & $50-84$ & 49 & NG & NG & $\mathrm{P}$ & Biopsy & $8-10$ & $370-555$ & $\begin{array}{l}\text { Increased } \\
\text { metabolism }\end{array}$ \\
\hline
\end{tabular}

NG: Not Given; R: Retrospective; P: Perspective; PSA: Prostate Specific Antigen; CT: Computed Tomography; FDG: Fluorodeoxyglucose; SUV: Standardized Uptake Value.

Table 1: Characteristics of Studies Included in the meta-analysis.

\begin{tabular}{|c|c|c|c|c|c|c|c|c|c|c|c|c|c|c|}
\hline \multirow[b]{2}{*}{ Study } & \multicolumn{14}{|c|}{ QUADAS criteria } \\
\hline & 1 & 2 & 3 & 4 & 5 & 6 & 7 & 8 & 9 & 10 & 11 & 12 & 13 & 14 \\
\hline LIU et al. [5] & $\mathrm{Y}$ & $\mathrm{Y}$ & $\mathrm{Y}$ & $\mathrm{Y}$ & $\mathrm{Y}$ & $U$ & $\mathrm{Y}$ & $\mathrm{Y}$ & $\mathrm{Y}$ & $\mathrm{N}$ & $\mathrm{N}$ & $\mathrm{Y}$ & $\mathrm{Y}$ & $\mathrm{Y}$ \\
\hline Richter et al. [14] & $\mathrm{Y}$ & $\mathrm{Y}$ & $\mathrm{Y}$ & $\mathrm{Y}$ & $\mathrm{Y}$ & $\mathrm{Y}$ & $\mathrm{Y}$ & $U$ & $\mathrm{Y}$ & $\mathrm{Y}$ & $\mathrm{Y}$ & $U$ & $\mathrm{Y}$ & $\mathrm{Y}$ \\
\hline Kit et al. [7] & $\mathrm{Y}$ & $\mathrm{Y}$ & $\mathrm{Y}$ & $\mathrm{Y}$ & $\mathrm{Y}$ & $\mathrm{N}$ & $\mathrm{Y}$ & $U$ & $U$ & $\mathrm{Y}$ & $\mathrm{Y}$ & $\mathrm{Y}$ & $\mathrm{Y}$ & $\mathrm{Y}$ \\
\hline García et al. [15] & $\mathrm{Y}$ & $\mathrm{Y}$ & $\mathrm{Y}$ & $\mathrm{Y}$ & $\mathrm{Y}$ & $\mathrm{Y}$ & $\mathrm{Y}$ & $\mathrm{N}$ & $\mathrm{N}$ & $\mathrm{Y}$ & $\mathrm{Y}$ & $\mathrm{Y}$ & $\mathrm{Y}$ & $\mathrm{Y}$ \\
\hline Beauregard et al. [13] & $\mathrm{Y}$ & $\mathrm{Y}$ & $\mathrm{Y}$ & $\mathrm{Y}$ & $\mathrm{Y}$ & $\mathrm{Y}$ & $\mathrm{Y}$ & $\mathrm{N}$ & $\mathrm{N}$ & $\mathrm{Y}$ & $\mathrm{Y}$ & $\mathrm{Y}$ & $\mathrm{Y}$ & $\mathrm{Y}$ \\
\hline Minamimoto et al. [6] & $\mathrm{Y}$ & $\mathrm{Y}$ & $\mathrm{Y}$ & $\mathrm{Y}$ & $\mathrm{Y}$ & $\mathrm{N}$ & $\mathrm{Y}$ & $\mathrm{N}$ & $\mathrm{N}$ & $\mathrm{Y}$ & $\mathrm{Y}$ & $\mathrm{Y}$ & $\mathrm{Y}$ & $\mathrm{Y}$ \\
\hline Hossein et al. [17] & $\mathrm{Y}$ & $\mathrm{Y}$ & $\mathrm{Y}$ & $\mathrm{Y}$ & $\mathrm{Y}$ & $U$ & $\mathrm{Y}$ & $\mathrm{Y}$ & $\mathrm{Y}$ & $\mathrm{N}$ & $\mathrm{N}$ & $\mathrm{Y}$ & $\mathrm{Y}$ & $\mathrm{Y}$ \\
\hline Yi et al. [16] & $\mathrm{Y}$ & $\mathrm{Y}$ & $\mathrm{Y}$ & $\mathrm{Y}$ & $\mathrm{Y}$ & $\mathrm{N}$ & $\mathrm{Y}$ & $\mathrm{Y}$ & $\mathrm{Y}$ & $\mathrm{Y}$ & $\mathrm{Y}$ & $\mathrm{Y}$ & $\mathrm{Y}$ & $\mathrm{Y}$ \\
\hline Ryogo et al. [18] & $\mathrm{Y}$ & $\mathrm{Y}$ & $\mathrm{Y}$ & $\mathrm{Y}$ & $\mathrm{Y}$ & $\mathrm{Y}$ & $\mathrm{Y}$ & $\mathrm{Y}$ & $\mathrm{Y}$ & $\mathrm{N}$ & $\mathrm{N}$ & $\mathrm{Y}$ & $\mathrm{Y}$ & $\mathrm{Y}$ \\
\hline Nishikant et al. [19] & $\mathrm{Y}$ & $\mathrm{Y}$ & $\mathrm{Y}$ & $\mathrm{Y}$ & $\mathrm{Y}$ & $U$ & $\mathrm{Y}$ & $\mathrm{N}$ & $\mathrm{N}$ & $\mathrm{Y}$ & $Y$ & $Y$ & $\mathrm{Y}$ & $Y$ \\
\hline
\end{tabular}

QUADAS: Quality Assessment of Diagnostic Accuracy Studies; N: no; U: Unclear; Y: Yes.

Table 2: QUADAS (appraisal) tool results.

revealed 378 articles. Reviewing titles and abstracts, 294 articles were excluded because of reviews, editorials or letters, case reports or case series. 25 articles were excluded due to absence of data to construct or calculate $2 \times 2$ tables. Six articles were excluded because of the sample sizes were less than 10. Finally, ten articles including 364 patients and 505 lesions, which published between 2009 and 2017, met the inclusion criteria for the meta-analysis [5-7,13-19]. The screenings of excluded articles were presented in Figure 1. The characteristics of the enrolled studies are presented in Table 1 . The mean age of patients ranged from 41 to 88 years. Of the ten included trials, four $[5,7,14,15]$ were retrospective trial and six $[13,6,16-19]$ were perspective trail. Nine studies $[5,7,13,19]$ have reported the Gleason scores which the scores were between 6 and 10 point. Only one study [6] has not given the Gleason scores. In terms of interpreted the positive of 18F-PET/CT imaging, three $[5,14,18]$ of the included trials were semi-quantitative method, two trails $[16,19]$ were qualitative method, and the other studies not given the interpreted method. There were nine studies reported the dose of 18-F FDG, and one study [5] has not given.

The methodological quality of the eligible 10 studies was assessed by the 'QUADAS' quality assessment tool (Table 2), and a total of 14 questions were applied for each study. Scores of all studies were more than 9 , indicating high quality.

1. Was the spectrum of patient's representative of the patients who will receive the test in practice?

2. Were the selection criteria clearly described?
3. Is the reference standard likely to correctly classify the target condition?

4. Is the time period between the reference standard and the index test short enough to be reasonably sure that the target condition did not change between the two tests?

5. Did the whole sample or a random selection of the sample receive verification using a reference standard of diagnosis?

6. Did patients receive the same reference standard regardless of the index test result?

7. Was the reference standard independent of the index test (i.e. the index test did not form part of the reference standard)?

8. Was the execution of the index test described in sufficient detail to permit replication of the test?

9. Was the execution of the reference standard described in sufficient detail to permit its replication?

10. Were the index test results interpreted without knowledge of the results of the reference standard?

11. Were the reference standard results interpreted without knowledge of the results of the index test?

12. Were the same clinical data available when the test results were interpreted as would be available when the test is used in practice?

13. Were uninterpretable/intermediate test results reported?

14. Were withdrawals from the study explained? 

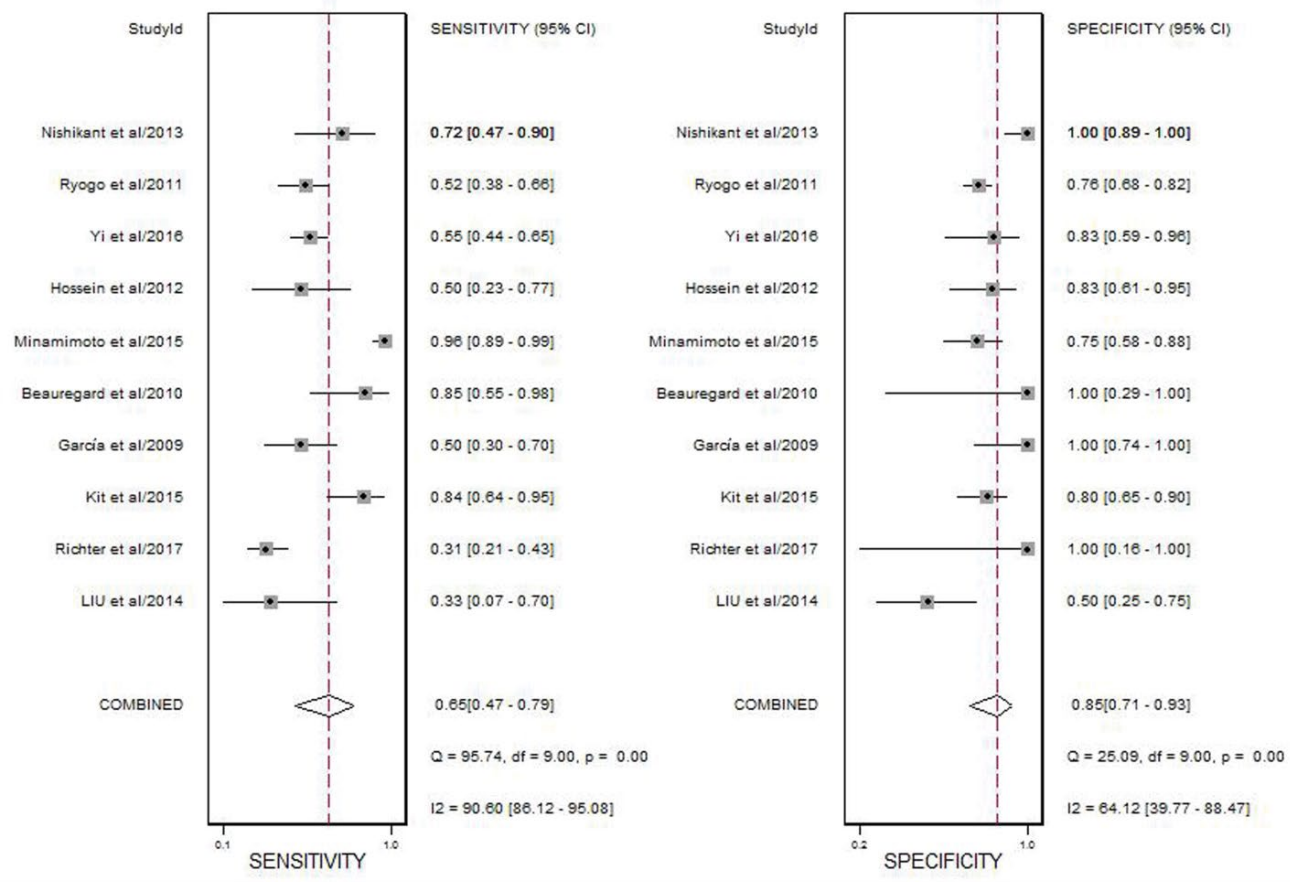

Figure 2: Forest plot of the sensitivity and specificity of 18F-FDG-PET/CT for the diagnosis of prostate cancer.

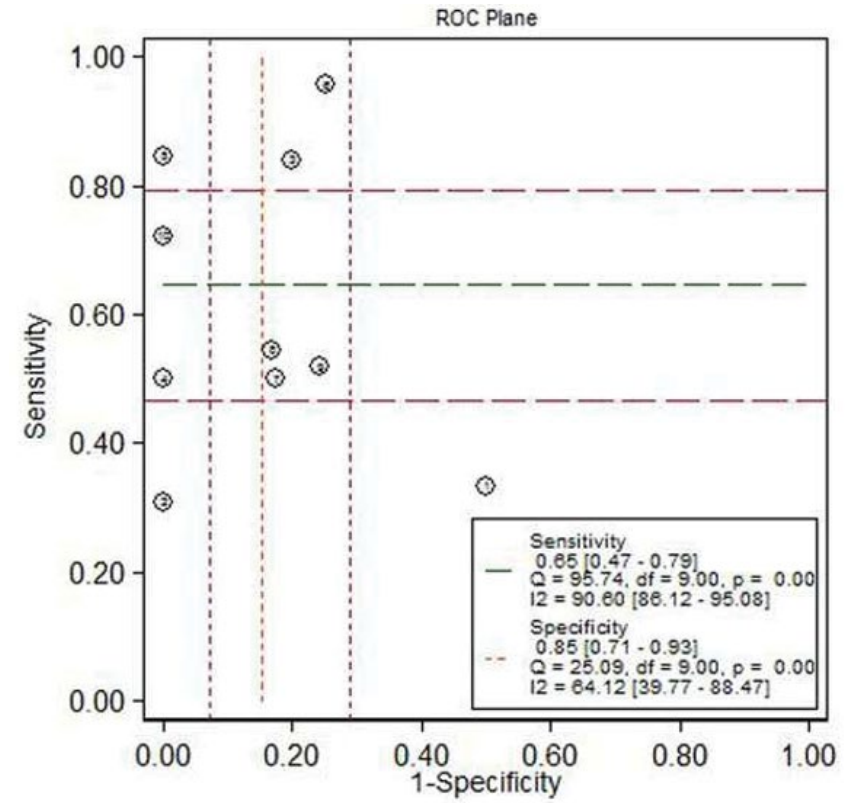

Figure 3: Receiver-operating characteristic plane plot of the sensitivity and specificity of 18F-FDG-PET/CT for the diagnosis of prostate cancer.

\section{Heterogeneity assessment}

The test of homogeneity indicated the present of statistical heterogeneity ( $Q$ value $=19.51, \mathrm{P}=0.000, \mathrm{I}^{2}=90 \%$ (95\% CI, 80-100). Besides, the proportion of heterogeneity likely due to threshold effect is 0.00 . Thus, it is unnecessary that meta-regression and subgroup analysis to be carried out to finding the potential sources of homogeneity.

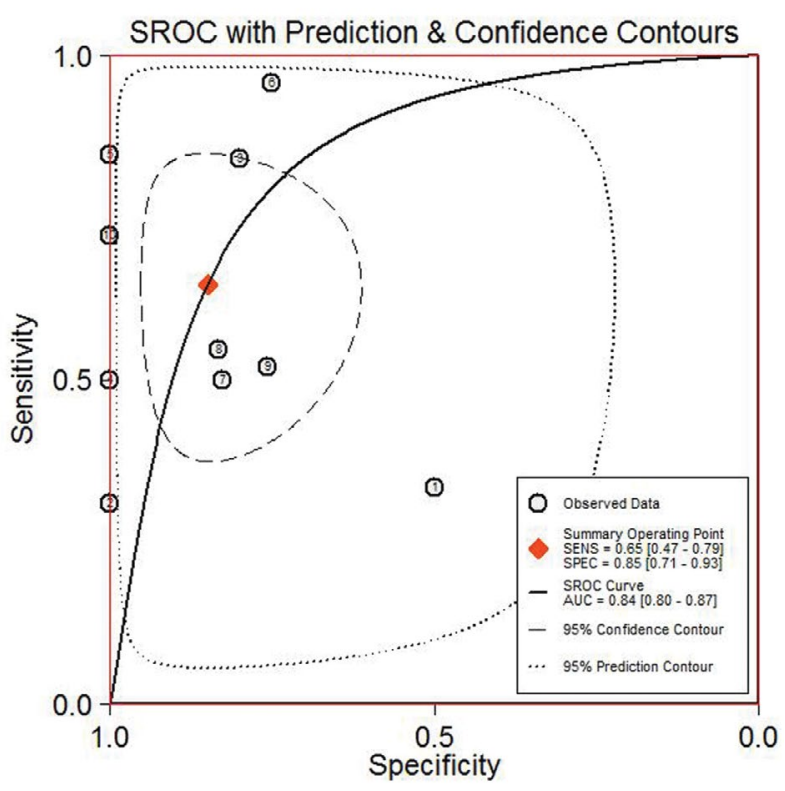

Figure 4: Hierarchical summary receiver-operating characteristic curve plot of the sensitivity and specificity of 18F-FDG-PET/CT for the diagnosis of prostate cancer.

From the forest plot (Figure 2), the included studies showed statistical heterogeneity in their estimate of sensitivity [ $Q$ value $=95.74$, $\left.\mathrm{P}=0.00 ; \mathrm{I}^{2}=90.60 .95 \% \mathrm{CI}(86.12-95.08)\right]$ and specificity $[(\mathrm{Q}$ value $=25.09$, $\left.\mathrm{P}=0.00 ; \mathrm{I}^{2}=64.12,95 \% \mathrm{CI}(39.77-88.47)\right]$ of $18 \mathrm{~F}-\mathrm{FDG} \mathrm{PET} / \mathrm{CT}$ on prostatic cancer, respectively. The pooled sensitivity and specificity of 18-F PET-CT in prostatic cancer were 0.65 (95\% CI, 0.47-0.79) and 


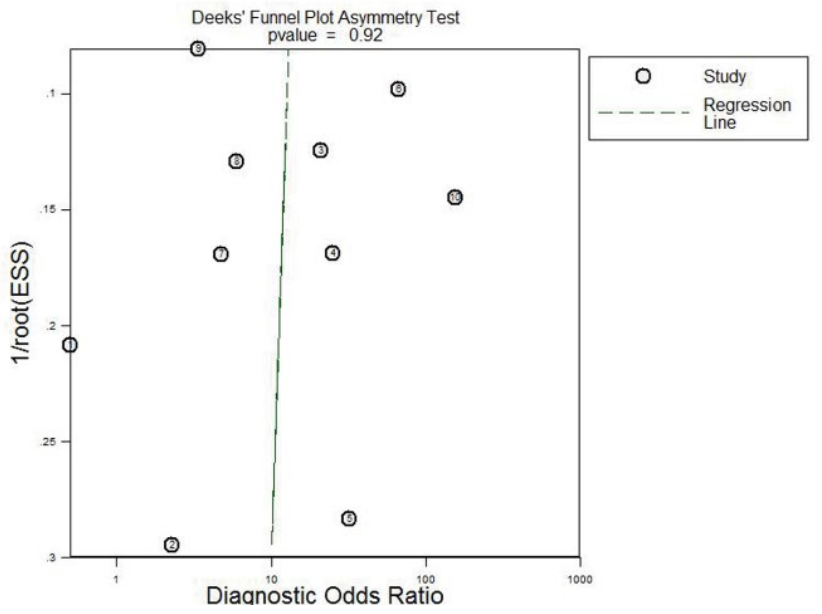

Figure 5: Deek's funnel plots for assessing the publication bias.

\begin{tabular}{|c|c|c|c|c|c|}
\hline & Coef. & Std. Err. & $\mathrm{t}$ & $\mathrm{P}>|\mathrm{t}|$ & $95 \% \mathrm{Cl}$ \\
\hline Bias & -1.18 & 10.76 & 0.11 & 0.92 & $26.00-23.62$ \\
\hline Intercept & 2.66 & 1.46 & 1.82 & 0.105 & $0.70-6.010$ \\
\hline
\end{tabular}

$\mathrm{Cl}$ : Confidence Interval.

Table 3: Statistical tests for small study effects/publication bias.

0.85 (95\% CI, 0.71-0.93), respectively (Figure 1).The overall PLR, NLR and DOR were 4.3 (95\% CI, 2.0-9.2), 0.41 (95\% CI, 0.25-0.68) and 10 (95\% CI, 3-32), respectively. The area under the summary ROC curve was $0.84(95 \% \mathrm{CI}, 0.8-0.87)$ with a hierarchical SROC graph showed Figures 3 and 4 . The more the curve approaches to the upper left corner, the higher the diagnostic efficacy is.

\section{Publication Bias}

In this meta-analysis, there is not exist publication bias in the included studies according to the Deek's test and the bias of test is 1.18 $(\mathrm{P}=0.92)$ (Table 3). Besides, the Deek's funnel plots a symmetric test showed symmetric $(\mathrm{P}=0.92)$, also indicating the publication bias is absent (Figure 5).

\section{Discussion}

To the best of our knowledge, this meta-analysis is the first to evaluate the diagnostic accuracy of 18F-FDG-PET or PET/CT in the evaluation of primary tumor in patients with prostatic cancer [20]. Several trails have applied the 18F-FDG PET/CT reporting different values of sensitivity, specificity and accuracy in this setting. However, the different study results are huge so that there are not inconsistent conclusion because of the diversity of research population, different design method, and various regions. In order to derive more robust estimates of the diagnostic accuracy of 18F-FDG PET/CT in this setting we pooled published studies. A systematic review process was adopted in ascertaining studies, thereby avoiding selection bias.

In our study, a meta-analysis was carried for published literatures and suggested that diagnostic efficacy of 18F-FDG PET/ CT was moderate in the prostate cancer, and the pooled sensitivity and specificity was $65 \%$ and $86 \%$, respectively. Some authors [19] prospectively evaluated the $18 \mathrm{~F}-\mathrm{FDG}$ PET/CT in patients with prostate cancers, and compared the results to $99 \mathrm{mTc}$ MDP bone scintigraphy (BS) and whole-body MRI, and they reported that 18F-FDG PET/CT showed significantly higher sensitivity and accuracy than WBMRI (96.2\% vs. $81.4 \%, \mathrm{P}<0.001,89.8 \%$ vs. $74.7 \%, \mathrm{P}=0.01)$ and $\mathrm{BS}(96.2 \%$ vs. $64.6 \%, \mathrm{P}<0.001,89.8 \%$ vs. $65.9 \%, \mathrm{P}<0.001)$ for the detection of skeletal lesions in prostate cancers. Meanwhile, the pooled diagnostic of ratio is 4.3 , which indicates that the differential effect of the diagnostic test is better. Furthermore, the value of the AUC (0.84) demonstrates that 18F-FDG-PET or PET/CT is accurate diagnostic methods under such circumstances.

However, the sensitivity of $18 \mathrm{~F}-\mathrm{FDG} \mathrm{PET} / \mathrm{CT}$ in diagnosing prostate cancer is slightly low, that is, the false positive rate is obvious. It is the reason that both prostatitis and prostate tumor can cause the prostate gland tissue taking in 18F-FDG and the gland had higher levels of glucose metabolism than normal tissue. In addition, the diagnostic efficacy of 18F-FDG PET/CT was higher than that of no metastasis in distant metastasis, such as bone, soft tissue or lymph nodes metastasis [13,15]. From the results of meta-analysis, the pooled specificity of $18 \mathrm{~F}-\mathrm{FDG}$ PET/CT is very high. In other words, the patients have great possibility anosis if the prostate gland has not obvious glucose metabolism increasing in the PET/CT imaging. Liu's [5] results indicated that the sensitivity of $18 \mathrm{~F}-\mathrm{FDG}$ PET-CT in identifying untreated primary lesions was only $33 \%$ (3/9), and got the conclusion that $18 \mathrm{~F}-\mathrm{FDG}$ PET-CT is not useful for the diagnosis of prostate cancer, but may aid with the detection of metastatic disease in appropriately selected patients.

To evaluate the heterogeneity of this study, our carried out the test of heterogeneity and the result indicated the present of statistical heterogeneity. Meanwhile, the threshold effect is the source of the heterogeneity, we have not carried out the meta-regression and subgroup analysis to be to finding the potential sources of homogeneity and using sROC curve and calculating the AUC of ROC is the best method to pooling data information.

The quality of this study is limited by statistical heterogeneity. But, the methodological quality was considered as high level by using the QUADAS tool in this study. Additionally, the current study reveals a symmetric funnel plots', indicating the publication bias is not exist.

\section{Conclusions}

The results of our meta-analysis suggested that 18F-FDG PET-CT were imaging methods with high accuracy in differential diagnosis of prostate cancer patients.

\section{References}

1. Goldwyn S, Lazinsky A, Wei H (2000) Promotion of health by soy isoflavones: Efficacy, benefit and safety concerns. Drug Metabol Drug Interact 17: 261-290.

2. Ondrusova M, Muzik J, Kliment J, Gulis G, Ondrus D (2011) Prostate cancer incidence and mortality in selected countries of Central Europe. Klin Onkol 24: 126

3. Rincón MA, Diaztejeiro BZ, Rioja ZJ, Díaz DL, Rodriguez FM, et al. (2011) How does endorectal MRI, PET-CT and transrectal ultrasound contribute to diagnosis and management of localized prostate cancer. Arch Esp Urol 64: 746-764.

4. Israel O, Kuten A (2007) Early detection of cancer recurrence: 18F-FDG PET/ CT can make a difference in diagnosis and patient care. J Nucl Med 48: $28 \mathrm{~S}$.

5. Liu Y (2014) Diagnostic role of fluorodeoxyglucose positron emission tomographycomputed tomography in prostate cancer. Oncol Lett 7: 2013-2018.

6. Minamimoto R, Loening A, Jamali M, Barkhodari A, Mosci C, et al. (2015) Prospective Comparison of 99mTc-MDP Scintigraphy, Combined $18 \mathrm{~F}-\mathrm{NaF}$ and 18F-FDG PET/CT, and Whole-Body MRI in Patients with Breast and Prostate Cancer. J Nucl Med 56: 1862. 
Citation: Liu X, Qi-lian R, Shi-liang Z, Jiang T, Su Z, et al. (2018) The Diagnostic Accuracy of 18F-FDG PET/CT in Prostate Cancer: A Systemic Review and Meta-analysis. J Nucl Med Radiat Ther 9: 352. doi: 10.4172/2155-9619.1000352

Page 6 of 6

7. How KN, Dugué AE, Sevin E, Allouache N, Lesaunier F, et al. (2016) Pairwise comparison of $18 \mathrm{~F}-\mathrm{FDG}$ and $18 \mathrm{~F}-\mathrm{FCH}$ PET/CT in prostate cancer patients with rising PSA and known or suspected second malignancy. Nucl Med Commun 37: 348-355.

8. Whiting P, Rutjes AW, Reitsma JB, Bossuyt PM, Kleijnen J (2003) The development of QUADAS: a tool for the quality assessment of studies of diagnostic accuracy included in systematic reviews. CJEBM 3: 25-25.

9. Huedo-Medina TB, Sánchez-Meca J, Marín-Martínez F, Botella J (2006) Assessing Heterogeneity in Meta-Analysis: Q Statistic or $\mathrm{I}^{2}$ index? Psychol Methods 11:193.

10. Higgins JPT, Thompson SG (2002) Quantifying heterogeneity in a metaanalysis - Higgins - 2002 - Statistics in Medicine - Wiley Online Library. Stat Med. 21: 1539-1558.

11. Irwig L, Macaskill P, Glasziou P, Fahey M (1995) Meta-analytic methods for diagnostic test accuracy. J Clin Epidemiol 48:119.

12. (2017) Corporation S. Stata Reference Manual, Release 12. Volume $3(\mathrm{~N}-\mathrm{R})$

13. Beauregard J-M, Williams S, DeGrado T, Roselt P, Hicks R (2010) Original article: Pilot comparison of 18 F-fluorocholine and 18 F-fluorodeoxyglucose $\mathrm{PET} / \mathrm{CT}$ with conventional imaging in prostate cancer. J Med Imaging Radiat Oncol 54: 325-332.

14. Richter JA, Rodríguez M, Rioja J, Peñuelas I, Martí-Climent J, et al. (2010) Dual
Tracer 11C-Choline and FDG-PET in the Diagnosis of Biochemical Prostate Cancer Relapse After Radical Treatment. Mol Imaging Biol 12: 210-217.

15. García JR, Soler M, Blanch MA, Ramírez I, Riera E, et al. (2009) PET/CT with (11)C-choline and (18)F-FDG in patients with elevated PSA after radical treatment of a prostate cancer. Rev Esp Med Nucl Imagen Mol 28: 95-100.

16. Yi C, Yu D, Shi X, Zhang X, Luo G, et al. (2016) The combination of $13 \mathrm{~N}$-ammonia and 18F-FDG whole-body PET/CT on the same day for diagnosis of advanced prostate cancer. Nucl Med Commun 37: 239.

17. Jadvar H, Desai B, Ji L, Conti PS, Dorff TB, et al. (2012) Prospective evaluation of $18 \mathrm{~F}-\mathrm{NaF}$ and $18 \mathrm{~F}-\mathrm{FDG}$ PET/CT in detection of occult metastatic disease in biochemical recurrence of prostate cancer. Clin Nucl Med 37: 637.

18. Minamimoto R, Uemura $H$, Sano F, Terao $H$, Nagashima $Y$, et al. (2011) The potential of FDG-PET/CT for detecting prostate cancer in patients with an elevated serum PSA level. Ann Nucl Med 25: 21-27.

19. Damle NA, Bal C, Bandopadhyaya GP, Kumar L, Kumar P, et al. (2013) The role of $18 \mathrm{~F}$-fluoride PET-CT in the detection of bone metastases in patients with breast, lung and prostate carcinoma: a comparison with FDG PET/CT and 99mTc-MDP bone scan. Jpn J Radiol 31: 262-269.

20. Delgado-Bolton RC, Fernández-Pérez C, González-Maté A, Carreras JL (2003) Meta-analysis of the performance of 18F-FDG PET in primary tumor detection in unknown primary tumors. J Nucl Med 44: 1301. 